\title{
Contextual violence and its link to social aggression: a study of community violence in Juárez
}

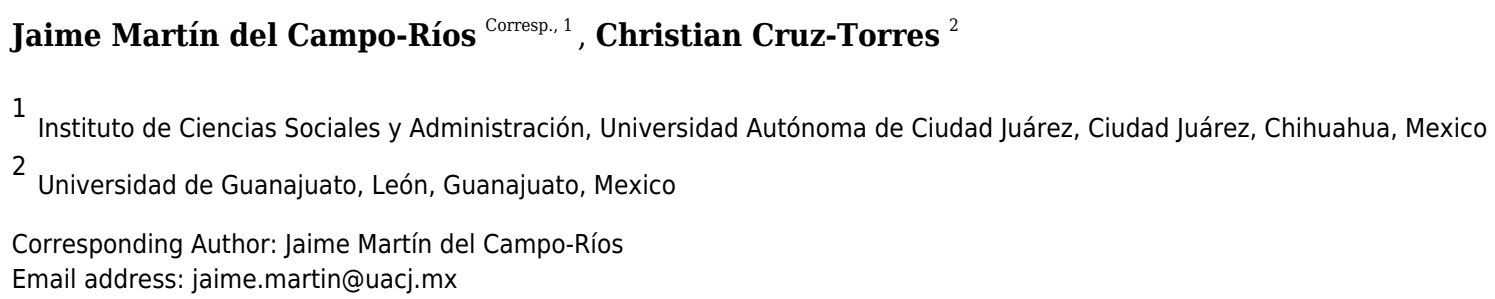

The city of Juárez, Mexico has been immersed in an atmosphere of violence and danger for more than a decade. Due to this violence, residents of Juárez may be at risk of severe contextual victimization, which occurs when individuals are indirectly affected by the physical and socio-cultural conditions of their violent communities through second-hand information (e.g., witnessing or hearing about violent acts in their everyday life). The objective of this study was to explore the effects of contextual victimization on variables related to community violence such as aggression, post-traumatic stress disorder (PTSD), and acceptance of violence. Data were collected from a sample of university students in Juárez ( $n=298$ ) using the Aggression Questionnaire (AQ), the Acceptance of Violence Scale (AVS), Checklist for PTSD Traits scale, and the Contextual Victimization by Community Violence scale (CVCV). Participants' responses were analyzed in structural equation models (SEM) to uncover the latent variables behind each scale and test the hypothesized effects of CVCV on PTSD, AQ and AVS. Good validity indexes and internal consistency of all instruments were confirmed. SEM show significant positive effects of contextual violence on PTSD and PTSD on the disposition to aggression, but not on the acceptance of violence. Also, the variance explained of PTSD and AQ found in the sample of women ( $20 \%$ of PTSD and $23 \%$ of AQ) is almost twice than in men's sample ( $9 \%$ for PTSD and $14 \%$ for $A Q$ ). 
1 Contextual violence and its link to social aggression: A study of community violence in Juárez

5 Jaime Martín del Campo-Ríos ${ }^{1}$, Christian Enrique Cruz-Torres ${ }^{2}$.

$6{ }^{1}$ Instituto de Ciencias Sociales y Administración, Universidad Autónoma de Ciudad Juárez,

7 Ciudad Juárez, Chihuahua, México

$8 \quad 2$ Universidad de Guanajuato, Campus León, Guanajuato, México

9

10 Corresponding Author:

11 Jaime Martín del Campo-Ríos

12 Av. Plutarco Elías Calles \#1210, Fovissste Chamizal, Ciudad Juárez, Chihuahua, México, C.P.

13 3231. Tel: +524491042491

14 Email address: jaime.martin@uacj.mx

16 Authors Jaime Martín del Campo Ríos and Christian Enrique Cruz-Torres declare that they have

17 no conflict of interest

18

19 'Declarations of interest: none" 
25

26

27

28

29

30

31

32

33

34

35

\section{INTRODUCTION}

\section{Demographics of violence in Juárez, Mexico}

\begin{abstract}
The city of Juárez, Mexico has been immersed in an atmosphere of violence and danger for more than a decade. Due to this violence, residents of Juárez may be at risk of severe contextual victimization, which occurs when individuals are indirectly affected by the physical and socio-cultural conditions of their violent communities through second-hand information (e.g., witnessing or hearing about violent acts in their everyday life). The objective of this study was to explore the effects of contextual victimization on variables related to community violence such as aggression, post-traumatic stress disorder (PTSD), and acceptance of violence. Data were collected from a sample of university students in Juárez $(n=298)$ using the Aggression Questionnaire (AQ), the Acceptance of Violence Scale (AVS), Checklist for PTSD Traits scale, and the Contextual Victimization by Community Violence scale (CVCV). Participants' responses were analyzed in structural equation models (SEM) to uncover the latent variables behind each scale and test the hypothesized effects of CVCV on PTSD, AQ and AVS. Good validity indexes and internal consistency of all instruments were confirmed. SEM show significant positive effects of contextual violence on PTSD and PTSD on the disposition to aggression, but not on the acceptance of violence. Also, the variance explained of PTSD and AQ found in the sample of women $(20 \%$ of PTSD and $23 \%$ of AQ) is almost twice than in men's sample (9\% for PTSD and 14\% for AQ).
\end{abstract}

The Mexican Drug War has caused some of the most disturbing concentrations of urban violence in the past two decades. From 2008 to 2012, the epicenter of this phenomenon was the border city of Juárez, which suffered historic levels of crime including high rates of femicide, armed assaults, car-jackings, extortions, and kidnappings. The collateral results of this violence were an estimated 10,000 children who were orphaned, 250,000 residents who fled from the city, 10,000 
50 businesses which closed, 30,000 jobs lost, and 25,000 houses which were abandoned (Nassif,

51 2012); in other words, everyday life in Juárez became paralyzed, affecting all social strata of the

52 city. There were more than 10,000 homicides in this period of time, which represents a quarter of

53 all drug-related deaths in Mexico, "more than the number of civilian casualties in Afghanistan

54 over the same period", and "more than double the number of U.S. troops killed in the entire Iraq

55 war" (Eisenhammer, 2014). By 2008 and 2009, homicides in Juárez were estimated to represent

$5627.6 \%$ of those committed in the entire country (Barraza, 2009). Current state of community

57 violence in Juárez has significantly decreased, although it is still perceived as an unsafe city.

58 According to the National Institute of Statistics and Geography (INEGI) $78.2 \%$ of its population

59 considers it a dangerous place to live (INEGI, 2018). Monthly homicides data of Juarez show

60 that the rates reached their last peak over 400 homicides per month in October 2010 (477

61 homicides registered), and although the numbers started to decrease since then, monthly

62 homicide rate fell by almost half, with 235 homicides. This general trend endured until present

63 times (INEGI, 2019).

64 Types of Violence Exposure and Effects

65 Echeburúa (2004) conceptualizes three different types of victims resulting from violence

66 exposure "a) Direct victims or primary sufferers. People directly affected by the aggression or

67 the traumatic event; b) Secondary or indirect victims. Included in this category are family

68 members and people that are close to the direct victims: those who are traumatized by the

69 physical and socio-cultural conditions after directly witnessing the violence; and c) Contextual

70 victims or affected: Those who are traumatized by the physical and socio-cultural conditions of

71 their violent communities, this category includes people who have been psychologically affected 
72 by serious events without suffering any direct losses or threats to their lives or their family."

73 (Gurrola-Peña, Balcázar, Esparza-Del Villar, Lozano-Razo \& Zavala-Rayas, J., 2018, p. 2).

74 Research provides evidence that the aforementioned types of violence exposure are associated

75 with an array of neurobiological, psychological, and attitudinal phenomena. For example, the

76 consequences of child maltreatment (i.e., primary or direct victim) can go so far as altering

77 children's neurobiological development (Perry, 1997; Teicher \& Samson, 2016). Furthermore,

78 specific cases of physical, sexual and emotional abuse, and physical and emotional neglect, exert

79 a prepotent influence on the trajectories of brain development, and constitute a major risk factor

80 for adult psychopathology (Teicher \& Samson, 2016). Many studies have reported that child

81 witnesses of homicides (i.e., secondary or indirect victims) can develop symptoms of post-

82 traumatic stress disorder (PTDS) that include re-experiencing traumatic events in play and

83 dreams, or when exposed to intrusive images and sounds associated with the events (Pynoos \&

84 Eth, 1984; Pynoos \& Nader, 1988). Witnessing acts of violence affects adults too. Shahinfar,

85 Kupersmidt \& Matza (2001) report that people exposed to violent acts tend to perceive positive

86 outcomes of being aggressive and increase reactive aggression via hostile attribution (e.g., the

87 tendency to interpret others' behaviors as having hostile intent) and response selection (e.g., the

88 process of choosing the appropriate action to take in response to a given stimulus) (Calvete \&

89 Orue, 2011). On the other hand, effects associated to contextual victimization have not been

90 thoroughly explored as to the effects of direct and indirect violence exposure.

\section{Objectives and Hypothesis}

92 It is widely believed that "children learn what they see" .... (or hear). This is an unfortunate truth

93 for Juárez in particular, where inhabitants of all ages have been exposed - whether directly or

94 indirectly - to violence in their everyday lives. It is believed that cities with higher levels of 
95 violence permeate an acceptance and tolerance of violence which appears to be strongly allowed

96 by cultural values considering it as a valid and even natural way to manage conflicts. These cities

97 face a significant risk for these values becoming standards (Hernández, Ramos Lira \& Méndez, 98 2004).

99 Based on the theoretical and contextual background of the violence suffered in Ciudad

100 Juárez in recent years, we propose the following research question:

101 Can contextual victimization (e.g., listening or witnessing violent acts; those exposed to

102 contextual violence specifically, not exposed to direct or indirect violence) generate emotional

103 effects that lead PTSD, higher levels of aggression and acceptance of violence?

104 The hypothesis of this study is that contextual victimization influence and alter the development

105 of social information-processing mechanisms resulting in a) an increasement in the emotional

106 affectations of citizens evaluated for PTSD [via the Checklist for PTSD Traits Scale (Pineda,

107 Guerrero, Pinilla \& Estupillán, 2002)]; b) a major acceptation of violence [reflectled in higher

108 scores on the Acceptance of Violence scale (AVS, Velicer, Huckel \& Hansen, 1989)]; c) the

109 disposition to being violent against others [predicting higher scores on the Aggression

110 Questionnaire (AQ, Buss, 1992)]; and d) given that the violence in Ciudad Juárez presents itself

111 in different modalities such as rape and femicide, it is hypothesized that there will be possible

112 differences in predictive models between men and women. As a secondary objective, a big five

113 personality scale (Ten-Item Personality Inventory; TIPI) was implemented in order to test an

114 alternative explanation derived from individual differences to the sensibility to threatening cues

115 (e.g., contextual violence).

116

117 METHODS \& INSTRUMENTS. 
118 Participants. Initially, a non-random sampling was performed with a recruitment of participants

119 via flyers, email invitations and snowball sampling. Three-hundred seventy-five undergraduate

120 students from the Autonomous University of Ciudad Juárez participated in the study. Data of 77

121 respondents were discarded and not considered for the statistical analyses due to participant

122 mortality, corrupted data, or inconsistent scores on some "trap" items. Thus, two-hundred and

123 ninety-eight participants were considered for the analysis; this sample was $52.3 \%$ male and

$12447.7 \%$ female, and had an average age of 19.28 years $(\mathrm{SD}=0.50)$. Participants were pursuing

125 diverse majors such as business administration, systems engineering, accounting, psychology

126 and graphic design. All were residents of Ciudad Juárez who had resided in the city for an

127 average of 17.6 years $(\mathrm{SD}=6.01)$. Among the sample, $95.3 \%$ of participants reported having

128 lived in Ciudad Juárez between 2008 and 2012.

129 Procedure. The Universidad Autónoma de Ciudad Juárez (UACJ) granted full ethical approval

130 to carry out the study within its facilities and with its students (Ethical Application Ref: CIEB-

131 2019-1-021). All measures were group-administered (20 to 25 individuals per session) via an

132 electronic survey system (Survey Monkey) in a university computer lab. Respondents were

133 physically separated during the completion of the questionnaire, and all respondents were asked

134 to put their mobile phones on Airplane Mode. General instructions were read aloud and

135 respondents were encouraged to ask the experimenter if they had any questions during the

136 session. Written consent was obtained for all participants. They were informed and reassured that

137 their responses would remain confidential.

138 Instruments. Five scales constituted the main instruments used in the current study.

139 The 34-item, 5-factor Contextual Victimization by Community Violence Scale (CVCV; Gurrola-

140 Peña, et al., 2018) was designed to identify the frequency with which young adults have been 
141 contextual victims of crimes committed in their social environment. Previous validation of the

142 instrument has yielded a reliability estimate of Cronbach's $\alpha=.94$ for item totals, and $59.52 \%$ of

143 the total variance explained by 5 factors. The first factor ( 8 items) evaluates non-witness

144 contextual victimization (e.g., "I have heard that in places where I go to have fun, someone was

145 shot"), explains $39.19 \%$ of the total variance, and has a Cronbach's $\alpha$ of .90 . The second factor

146 (7 items) focuses on witness contextual victimization (e.g., "I have seen how a person has been

147 wounded with a weapon in the places that I frequent"), explains $7.28 \%$ of the total variance and

148 has a Cronbach's $\alpha$ of .85 . The third factor ( 8 items) centers on contextual victimization in the

149 neighborhood (e.g., "I have heard that in my neighborhood people have been kidnapped"),

150 explains $5.45 \%$ of the total variance and has a Cronbach's $\alpha$ of .88 . The fourth factor (6 items)

151 concerns contextual victimization in recreational places (e.g., "I have heard that in places where I

152 usually go for fun people have been killed"), explains $4.64 \%$ of the total variance and has a

153 Cronbach's $\alpha$ of .86. The fifth factor (5 items) relates to victimization at school (e.g., "I have

154 heard that someone at my school has been shot"), explains 3.04\% of the total variance and has a

155 Cronbach's $\alpha$ of .80.

156 The next instrument was the Aggression Questionnaire (AQ; Buss \& Perry, 1992), which

157 has been widely used to assess different dimensions of aggression. It includes 29-items scored on

158 a 5-point Likert scale $(1=$ uncharacteristic of me, $5=$ very characteristic of me) grouped into 4

159 factors: (a) anger (A; 7 items), (b) hostility (H; 8 items), (c) verbal aggression (VA; 5 items), and

160 (d) physical aggression (PA; 9 items). The version used in this study was validated with a young

161 sample of Mexicans (Matías et al., 2013), and is based on the Aggression Questionnaire for

162 Spanish pre-adolescents and young adults (AQ) (Santisteban \& Alvarado, 2009). Both maintain

163 the structure of Buss and Perry's original 1992 version of the AQ. Internal consistency for the 
164 Mexican version of the AQ shows Cronbach's $\alpha=0.92$, indicating that this version of the AQ

165 instrument is valid and reliable for use with adult Mexican populations.

166 The third instrument, the Checklist for PTSD Traits Scale (Pineda, Guerrero, Pinilla \&

167 Estupillán, 2002), aims to diagnose PTSD symptoms in individuals that live in violent

168 populations. The scale consists of 24 items based on the symptoms of PTSD consistent with

169 DSM-IV criteria (e.g., "I constantly have thoughts that remind me of the unpleasant situation and

170 cause me a lot of anguish"), scored using a 4-point Likert scale ( 1 = totally disagree; $4=$ totally

171 agree). Pineda et al. (2002) report that the scale has good discriminant capability, high levels of

172 sensibility and specificity, and excellent internal consistency (Cronbach's $\alpha=0.97)$. The scale

173 was previously validated in Mexico with a sample of youths exposed to social violence reporting

174 (Chronbach's $\alpha=0.92$ ) (Chávez-Valdez, Esparza-Del Villar \& Riosvelasco-Moreno, 2020).

175 The fourth instrument, the Acceptance of Violence Scale (AVS, Velicer, Huckel \&

176 Hansen, 1989), is a 14-item, three factor-solution scale validated in Mexico (Hernández, Ramos

177 Lira \& Méndez, 2004) that evaluates attitudes of acceptance of force and coercion to resolve

178 conflicts; and the tolerance of the use of violence in a variety of situations. Responses are scored

179 using a 4-point Likert scale ( 1 = totally disagree; 4 = totally agree). The internal reliability

180 estimate for the global scale is Cronbach's $\alpha=.83$. For individual factors, reliability estimates

181 are, $\alpha=.89$ for the acceptance of family violence factor ( 5 items; e.g., "It is a right of the couple

182 to hit the other in the face if they flirt with others") ; $\alpha=.71$ for acceptance of violent disciplinary

183 tactics (4 items; e.g., "A child who is usually disobedient should be punished physically"); and $\alpha$

$184=.67$ for acceptance of military violence (5 items; e.g., "The government must send armed

185 soldiers to control the violent demonstrations"). 
187 Swann, 2003), a 10-item instrument that measures responses on five factors ("Big Five"

188 personality traits): extraversion, agreeableness, conscientiousness, neuroticism (or emotional

189 stability), and openness to experience factors. This short inventory contains ten pairs of two trait

190 descriptors (e.g., extraverted/enthusiastic) that aim to establish a broad coverage of traits whilst

191 trying to avoid redundancy. Responses are scored on a 7-point scale $(1=$ Strongly Disagree to 7

$192=$ Strongly Agree; 5 reverse-scoring items). Adequate test-retest reliability and levels of

193 convergent and discriminant validity and relationships with external correlates are reported in

194 Gosling et al. (2003). Although the authors stress that the TIPI has only two items that result in

195 low internal consistency estimates, the main goal of the scale was not to offer high alphas or

196 good Confirmatory Factor Analysis fits. Although the TIPI is yet to be validated with a Mexican

197 population, it has been translated and validated in several countries, always showing adequate

198 levels of internal consistency and validity [e.g. two German versions (Herzberg \& Brähler, 2006;

199 Muck et al., 2007), Dutch (Hofmans, Kuppens \& Allik, 2008), Italian (Chiorri, Bracco, Piccinno,

200 Modafferi, \& Batinni, 2015), Japanese (Oshio, Abe, \& Cutrone, 2012), and a Spanish translation

201 (Romero, Villar, Gómez-Fraguela, \& López-Romero, 2012) among others], which makes the

202 TIPI a widely applicable instrument with a potential for large-scale cross-cultural studies.

203 Moreover, the TIPI was not the central instrument in this study; the only factor considered was

204 emotional stability, given that it could approximate whether individuals are more sensitive in

205 general and easily affected by contextual violence.

206

207 Data analysis. Since the instruments were developed and validated in samples other than those 208 analyzed in this study, the internal structure and consistency of each instrument were verified 
209 before the hypothesis test analysis. All responses were subjected to exploratory factorial analysis

210 of maximum likelihood with varimax rotation. The minimum extraction criterion was set to an

211 eigenvalue of 1 . Items with loadings lower than .4 on all factors were discarded from the

212 analysis. Once the factorial structure of each scale was established the internal consistency of

213 each factor was calculated using Cronbach's alpha. The indicators for each factor were formed by

214 averaging the items with loadings greater than .4 onto their factor. Once the factors were

215 identified, structural equations modeling (SEM) of maximum likelihood in AMOS 22 (Arbuckle,

216 2013) was performed to test the hypothesis of positive effects of CVCV on PTSD, and the

217 positive effects of the CVCV on disposition to aggression, as evaluated by the AQ. Finally, given

218 that violence in Ciudad Juárez has victimized men and women differently, possible differences in

219 models between men and women were explored by multigroup comparison in AMOS software

220 (Arbuckle, 2013).

221 A potential confusing factor is that the perception of contextual violence may be affected

222 by individual differences, given that more sensitive people are expected to report higher levels of

223 perceived violence. To explore this possibility, high and low groups were formed in the

224 measurement of emotional stability of the TIPI. The sample was divided into high and low levels

225 of this variable, then comparing the means of both groups in contextual violence measurements.

226 If significant differences between the two groups were identified, it could be assumed that

227 emotional stability is a strange variable that must be statistically controlled in the models.

230 RESULTS 
231 Table 1 shows the main psychometric and descriptive statistics of each factor identified by the

232 exploratory factor analysis on each instrument. The analysis for the CVCV questionnaire

233 retained 33 of the original 34 items proposed by Gurrola-Peña et al. (2018), eliminating the item

234 "I have seen someone get stabbed in my school" for loading values less than 0.4 for all the

235 factors. The five-factor solution obtained explained $60.92 \%$ of the variance of responses, and

236 corresponded to the conceptual content of the original scale. The first factor was called "Non-

237 witness contextual victimization" given that it contained items related to hearing about violent

238 events in areas related to one's daily life (e.g., "I have heard that someone has been shot in my

239 neighborhood"; "I have heard that in places that I usually go someone has been shot"). The

240 second factor was named "Contextual victimization in the neighborhood" for comprising items

241 that relate to having heard about (e.g., "I heard that someone has been shot in my neighborhood")

242 or witnessed (e.g., "I have seen drug trafficking in my neighborhood") threatening situations in

243 areas near the home. The third factor was named "Contextual victimization in recreational areas"

244 because it contained items related to hearing about acts of violence in recreational areas (e.g., "I

245 have heard that in places where I go for fun people have been shot"). The fourth factor was

246 named "Contextual victimization at school" since it contains items related to hearing (e.g., "I

247 have heard that someone has been shot in my school") or witnessing (e.g., "I have seen how

248 someone has been beaten in my school") violent acts at school. The fifth factor was called

249 "Witness contextual victimization", because it is comprised of items that refer to having

250 witnessed violent acts in areas related to one's daily life (e.g., "I have seen someone being shot

251 in places I usually frequent"; "I have witnessed a non-weapon assault in places where I usually

252 go for fun"). To explore possible differences in contextual violence between men and women,

253 the averages in each indicator were compared using Student's t-tests. The results only identify 
254 statistically significant, although very small, differences in non-witness contextual victimization

$255(\mathrm{t}=2.17, \mathrm{df}=296, \mathrm{p}=.030$, Men $\mathrm{M}=2.21$, Women $\mathrm{M}=1.98)$ and contextual victimization in

256 school $(\mathrm{t}=-1.98, \mathrm{df}=283.34, \mathrm{p}=.048$, Men $\mathrm{M}=1.27$, Women $\mathrm{M}=1.39)$. The other three forms

257 of contextual violence show averages that can be considered equivalent between both groups (t's $258<1.47, \mathrm{p}>.141)$.

259 Analysis of the PTSD checklist showed a structure of two factors plus an indicator that

260 contained only two items, explaining together $59.19 \%$ of the variance with the 24 original items.

261 The first factor was labelled "Outcomes" given that it comprises items centered around changes

262 in emotional state and everyday life provoked by traumatic events (e.g., After what happened, I

263 have many difficulties in my relationships with others.). The second factor was named

264 "Memories", containing items related to the recurrence of memories associated with the

265 traumatic event (e.g., "I feel bad when something reminds me of the situation") and the strategies

266 used to cope with them (e.g., I always avoid thinking or talking about what happened.). The third

267 factor was named "Event" and only has two items, but was kept since both items referred to

268 having recently experienced a violent event (e.g., "Lately I have experienced at least one

269 situation related to death or threats against my life or to other people related to me") that was

270 considered traumatic (e.g., "because of this situation I have experienced a lot of anguish or

271 excessive fear.”), in addition to explaining an adequate amount of variance (see Table 1).

272 The analysis of the Aggression Questionnaire identified four factors consisting of 23 of

273 the original 29 items of the scale, which together explained $49.75 \%$ of the variance in responses.

274 Six of the items were discarded because they presented loadings of less than 0.4 on all factors.

275 The first factor was named "Punching", for referring to the disposition to enter into a conflict and 276 hit other people (e.g., If they provoke me enough, I can hit another person). The second factor 
277 was named "Paranoia", because it refers to a general distrust of other people and the possibility

278 of being hurt by them (e.g., "When people are particularly friendly, I suspect their real

279 intentions"). The third factor was named "Anger", since its items refer to the tendency to feel

280 angry without a particular reason (e.g., Sometimes I get very angry for no reason). The last factor

281 was called "Arguing", since its items refer to the willingness to easily enter into discussions with

282 other people (e.g., "When I do not agree with my friends, I argue with them.").

283 Analysis of the Acceptance of Violence Scale yielded a three-factor structure containing

28412 of the original 14 items which together explained $53.86 \%$ of the total variance in responses.

285 The first factor was named "Acceptance of violence against children", as it contained items such

286 as "A child who is habitually disobedient must be punished physically". The second factor was

287 named "Acceptance of couple violence", as it contained items such as "It is a right of the couple

288 to hit the other if they are insulted or ridiculed". In the original proposal, this factor contained

289 items about violence against children and was named "Family violence", but in this analysis it

290 only contained items related to violence in couples. The third factor was named "Acceptance of

291 military violence" containing items such as "Our country should be aggressive internationally

292 using military force".

293

294

295

296

297

298

299

300
Insert Table 1

Once the factors were identified, the data were analyzed using the SEM of maximum significant factorial loads of all observed variables on their respective latent variables, with $\mathrm{CR}$ values among 6.36 and 15.78 with $p<.001$., confirming that the structure of the instruments identified by the exploratory factor analysis was adequate for this sample. The model confirms a positive and significant effect of contextual violence on $\operatorname{PTSD}(\mathrm{B}=.13, \mathrm{CR}=3.88, \mathrm{p}<.001)$, 
301 explaining $6 \%$ of its variance. Contextual violence $(\mathrm{B}=.08, \mathrm{CR}=2.07, \mathrm{p}=.038) \mathrm{PTSD}(\mathrm{B}=$

$302.32, \mathrm{CR}=4.25, \mathrm{p}<.001)$ had positive direct effects on disposition to aggression, which added to

303 an indirect effect of contextual violence on disposition to agresion $(B=.04, z=2.86, p=.004)$

304 (Sobel, 1986), explain together 13\% of the variance. However, the fit of this model was not

305 adequate $\left(\mathrm{Chi}^{2}=140.18, \mathrm{gl}=51, \mathrm{p}<.001, \mathrm{RMR}=.036, \mathrm{GFI}=.92, \mathrm{AGFI}=88, \mathrm{CFI}=.94\right.$,

306 RMSEA $=.077[$ CI $90 \%=.062, .092])$. An analysis of the residual covariances of the model

307 made it possible to identify that these discrepancies derive mainly from the contextual violence

308 observed variables, which are all part of its latent variable, but only "at school" and "in the

309 neighborhood" variables have a predictive effect on PTSD. This would seem to indicate that the

310 complete construct of contextual violence is not necessary for the prediction of PTSD. The

311 model is more parsimonious if we take only the indicators of contextual violence at school and in

312 the neighborhood, which could also be considered the most common locations for the sample in

313 this study. It is noteworthy that these two factors have a more important effect than variables

314 related to direct exposure to violence such as the "witnessed violence" factor.

Insert Figure 1

With this model as a backdrop, a new model was tested (see Figure 2) which preserved only the factors of contextual violence at school and neighborhood for their significant weights on the PTSD. These variables were preserved allowing free covariation between their measurement errors as part of the same construct, but contextual violence was removed as a

322 latent variable, while three of its five original observed variables were eliminated as well. The

323 errors of the AQ variables "punching" and "arguing", as well as the errors of the variables of the 
324 PTSD dimension "event" and "consequences", were also allowed to freely correlate. It is

325 interesting to note that the covariation between the "event" and "consequences" variables is

326 negative $(\mathrm{B}=-. .10, \mathrm{CR}=-3.69, \mathrm{p}<.001)$, which could indicate a sustained effort to overcome

327 the traumatic event by continuing with everyday life (i.e., those most exposed to traumatic events

328 would be more aware of the importance of continuing their routine activities).

In this new model, contextual violence at school $(\mathrm{B}=.13, \mathrm{CR}=2.55, \mathrm{p}<.011)$ and in the

330 neighborhood $(\mathrm{B}=.13, \mathrm{CR}=5.08, \mathrm{p}<.001)$ together explained the $13 \%$ of the variance in

331 responses to the PTSD questionnaire. In turn, $\operatorname{PTSD}(\mathrm{B}=.23, \mathrm{CR}=3.82, \mathrm{p}<.001)$, contextual

332 violence at school $(\mathrm{B}=.06, \mathrm{CR}=2.53, \mathrm{p}=.011)$ and in the neighborhood $(\mathrm{B}=.06, \mathrm{CR}=1.26, \mathrm{p}$

$333=.205$ ) had positive effects on disposition to violence, although this last one is not statistically

334 significant. These direct effects added to indirect effects of contextual violence at the school $(\mathrm{B}=$ $335.03, \mathrm{z}=2.13, \mathrm{p}=.036)$ and in the neighborhood $(\mathrm{B}=.03, \mathrm{z}=3.07, \mathrm{p}=.002)($ Sobel, 1986),

336 explain $17 \%$ of the variance of responses to the AQ. This indicates that $17 \%$ of the explained 337 variance of the AQ is given by a direct effect of PTSD, but part of this variance is explained by 338 contextual violence at school and in the neighborhood. This model shows better goodness of fit $339(\mathrm{RMR}=.020, \mathrm{GFI}=.97, \mathrm{AGFI}=.93, \mathrm{CFI}=.97)$, although the Chi-square indicator and RMSEA 340 keep signaling significant discrepancies between the relationships established in the model and

341 those observed in the data $(\chi 2=41.63, \mathrm{df}=21, \mathrm{p}=.005)$, and an acceptable possibility to

342 generalize this model to the population from which the sample was extracted (RMSEA $=.058$

$343[$ CI 90\% $=.031, .083])($ Kline, 2011). While Browne \& Cudeck (1993) propose that maximum

344 values of .08 for RMSEA indicate a reasonable goodness of fit, more demanding criteria such as

345 that of Hu and Bentler (1999) propose that levels above .06 indicate that the model could not be

346 generalized to the population from which the sample was extracted. 
$352[\mathrm{IC} 90 \%=.030, .069])$, but not for Chi-squared indicator $\left(\chi^{2}=72.90, \mathrm{df}=42, p=.002\right)$.

violence at school $(\mathrm{B}=.06, \mathrm{z}=2.18, \mathrm{p}=.028)$ and in the neighborhood $(\mathrm{B}=.06, \mathrm{z}=2.65, \mathrm{p}$ $=.008$ ) remain statistically significant, and added to direct effects in the model explain $20 \%$ of

contextual and neighborhood violence on aggression, and that the direct effects are not increases the predisposition to aggression only when they are high enough to increase PTSD. contextual violence in the neighborhood on $A Q(C R=2.13, p=.032)$. Indirect effects of violence

367 at school $(\mathrm{B}=.02, \mathrm{z}=1.23, \mathrm{p}=.21)$ and in the neighborhood $(\mathrm{B}=.02, \mathrm{z}=1.90, \mathrm{p}=.056)$ were 368 not statistically significant (Figure 4). This model results clearly more adequate for women than 
369 for men, considering that explained variance decreased to 9\% for PTSD and 14\% for AQ, almost

370 half than in the women's model.

371

372

373

374 375

376

377

378

379

380

381

382

383

384

385

386

387

388

389

390

391

Insert Figure 4

These differences between both models would explain the significant discrepancies observed in the $\chi^{2}$ indicator of the unrestricted model. As the equivalence between both models was not guaranteed in this first level, no comparison was performed in the following levels of restrictions.

In order to test the hypothesis of the effects of contextual violence and PTSD on the acceptance of violence, the AQ was replaced with the Acceptance of Violence measurement in the previous model. The resulting model did not confirm our hypothesis. There was adequate adjustment of the model $\left(\chi^{2}=13.68, \mathrm{df}=17, \mathrm{p}=.68, \mathrm{RMR}=.011, \mathrm{GFI}=.98, \mathrm{AGFI}=.97, \mathrm{CFI}\right.$ $=1.00$, RMSEA $<.001[$ CI 90\% $=.00, .04])$, but an explained variance of $0 \%$.

A possible alternative explanation of the results is that the perception of contextual violence may be affected by participant individual differences, in that more sensitive people would tend to report higher levels of perceived violence. To explore this possibility, high and low groups were formed in the measurement of emotional stability of the Ten-Item Personality Inventory (TIPI; Gosling, 2003) based on the median value (4.5). Comparisons were made between both groups using the Student's $t$ test in the indicators of contextual violence at school and in the neighborhood. The results do not identify statistically significant differences in any of the two indicators of violence, with values of $t<1.57$ and $p>.119$ for both comparisons, indicating that reports of contextual violence were not affected by emotional stability.

Peer) reviewing PDF | (2019:12:43733:1:1:NEW 25 Feb 2020) 


\section{DISCUSSION}

393 The current study examined whether degree of contextual violence could determine levels of

394 PTSD and disposition to aggression. The SEM analysis only partially confirmed the hypothesis

395 that contextual violence was predictive of the emotional affectations associated with PTSD. This

396 is because only the indicators of violence at school and in the neighborhood were able to predict

397 any variance in responses to the PTSD instrument. In addition, our analysis showed that these

398 variables were only predictive of PTSD in women, and that the only predictor for men was

399 violence in the neighborhood. As the responses came from a sample of students, it makes sense

400 that the main predictors of PTSD would be violence in the neighborhood and at school, as these

401 are likely to be their most frequented locations. However, the result that violence at school is

402 predictive for women but not men may indicate that school is perceived as a safe space by men

403 only. It is also notable that the factors of contextual violence at school and in the neighborhood,

404 composed of items that mainly relate to hearing that violent acts have occurred, have a greater

405 predictive capacity than factors such as witnessed violence. This may be due to the fact that signs

406 of violence in highly-frequented locations have a greater impact than those in less-frequented

407 areas or in non-specific locations, even if it was personally witnessed.

408 Indirect effects of contextual violence on AQ were also identified, implying that the

409 PTSD is mediating this relationship. However, the comparison analysis between groups

410 confirmed this result only in the sample of women. This difference may be since the levels of

411 variance explained, both of PTSD and AQ, are markedly higher in women than in men. In this

412 regard, it should be considered that the level of contextual violence in the school reported by

413 women is barely significantly higher than that of men, and their averages of contextual violence

414 in the neighborhood are equivalent. That is, with clearly close levels of contextual violence, the 
415 harmful effects on emotional health (PTSD) and its willingness to aggression (AQ) are more

416 important in women. In this regard, it should be recognized that these scales do not evaluate

417 some forms of violence that only women typically suffer such as sexual harassment, whether in

418 work or educational environments, which represents a solid research objective for new projects

419 in this same line.

420 It would be interesting to explore whether the level of education affected the results.

421 Considering that higher education is associated with rational thinking, it is interesting to consider

422 whether university students who are over-exposed to violence would not accept or justify the use

423 of violence (conscious or rational thinking), even if they tend to rely on violent

424 behaviors (unconscious or reactive acting) in threatening situations. We also propose that

425 community violence studies would benefit from moving beyond common sampling criteria such

426 as age, sex, and education level in order to shed further light on the patterns of social-cognitive

427 functioning among individuals exposed to violence. Due to resource and time restraints, this

428 rational could not be followed in the current study, and as such constitutes a serious limitation.

429 Shafinkar (2011) suggests two ways to accomplish this. Firstly, it is important to carefully

430 consider the modality of exposure to violence of the participants (e.g., if studying effects of

431 indirect exposure, filter those who have had direct exposure to violence). Secondly, the severity

432 of the exposure is a factor that must be emphasized and included in analysis.

433 The current study confirmed the hypothesis on the role of emotional affectations (PTSD)

434 as potential generators of aggression or at least a tendency to attack others. The direct effects of

435 contextual violence on disposition to aggression show that contextual violence predisposes one

436 to aggression against others in general, both by itself and through its emotional affectations.

437 Several notable differences were identified between men and women models. Although in 
438 absolute terms $23 \%$ explained variance in the model with women may seem like a small amount,

439 it should be considered that in relative terms, it is twice the amount of variance explained in the

440 model with men. This difference may derive from the increased sense of vulnerability among

441 women from exposure to rape, kidnapping, domestic violence or human trafficking; all these

442 types of crimes with notably high rates in Juárez City.

443 The elements uncovered in the models presented here could potentially relate to the

444 spread of violence, a phenomenon whose dynamics have been studied among criminal groups in

445 Mexico (Osorio, 2015) but not among general populations. Previous studies have shown that

446 increases in a city's violence show patterns similar to those of an epidemic (Berkowitz \&

447 Macaulay, 1971), where exposure to especially violent events transforms existing norms and the

448 meaning, for example, of "being violent" from an undesirable attribute to a characteristic that

449 provides respect and security. One interpretation of this phenomenon is that as new norms spread

450 among the population to the extent, those endorsing them are more likely to "adjust" (in

451 evolutionary terms). As a consequence, the adopters of these norms can gain access to better

452 resources and develop better solutions for common problems such as exposure to violence

453 (Fagan, Wilkinson, \& Davies, 2007).

Although no effects on norms related to acceptance of violence were identified in this

study, the instruments used did not cover aspects such as acceptance of the possession of weapons, the legitimacy of revenge, the exercise of vigilante justice, or other similar norms which would imply a greater willingness of citizens to join the spiral of violence in their city, 458 i.e., what Eisenhammer (2004) has called "bare life". These elements remain a vein for future 459 research to explore. 


\section{CONCLUSIONS}

462 While the model in this investigation is not a definitive model for contextual victimization, we

463 do consider it as a starting point for the study of contextual violence consequences, given that it

464 has been centered mainly on its measure and not on its effects. Future research could also

465 improve by measuring whether the participants have or have not been exposed to direct or

466 indirect violence, in order to limit possible correlates on contextual victimization only. Finally,

467 though this line of research centers on understanding the underlying mechanisms of violence

468 exposure, it must be stressed that the implicit goal of studies in this area should be to improve

469 interventions to reduce aggressive behavior in individuals exposed to violence (Calvete \& Orue,

470 2011), and reduce community violence as a result.

471

472 REFERENCES

473 Arbuckle, J. L. (2013). Amos (Versión 22.0) [Programa de cómputo]. Chicago: SPSS.

474 Aziz Nassif, A. (2012). Violencia y destrucción en una periferia urbana: El caso de Ciudad Juárez, 475 México. Gestión y política pública, 21(spe), 227-268.

Barraza, L. (2009). Diagnóstico sobre la realidad social, económica y cultural de los entornos locales para el diseño de intervenciones en materia de prevención y erradicación de la violencia en la región norte: el caso de Ciudad Juárez. Chihuahua: Gobierno Federal.

Berkowitz, L., \& Macaulay, J. (1971). The contagion of criminal violence. Sociometry, 238-260. 
483 Browne, M. W., \& Cudeck, R. (1993). Alternative ways of assessing model fit. In K. A. Bollen

484 \& J. S. Long (Eds.), Testing structural equation models (136-162). Newbury Park, CA: $485 \quad$ Sage.

486 Buss, A. H., \& Perry, M. (1992). The aggression questionnaire. Journal of personality and social $487 \quad$ psychology, 63(3), 452.

488 Calvete, E., \& Orue, I. (2011). The impact of violence exposure on aggressive behavior through 489 social information processing in adolescents. American Journal of Orthopsychiatry, 81(1), $490 \quad 38-50$.

491 Chávez-Valdez, S. M., Esparza-Del Villar, O. A., \& Ríos Velasco-Moreno, L. (2020). Validation 492 of a Scale of Post-traumatic Stress Traits in the Mexican Youth Exposed to Social 493 Violence. Journal of Aggression, Maltreatment \& Trauma, 1-13.

494 Chiorri, C., Bracco, F., Piccinno, T., Modafferi, C., \& Battini, V. (2015). Psychometric 495 properties of a revised version of the Ten Item Personality Inventory. European Journal of $496 \quad$ Psychological Assessment.

497 Echeburúa, E. (2004). Superar un trauma: el tratamiento de las víctimas de sucesos violentos. $498 \quad$ Pirámide.

499 Eisenhammer, S. (2014). Bare life in Ciudad Juárez: violence in a space of exclusion. Latin 500 American Perspectives, 41(2), 99-109.

501 Fagan, J., Wilkinson, D. L., \& Davies, G. (2007). Social contagion of violence. in D. J. Flannery, 502 A. T. Vazsonyi, I. D. \& Waldman, (Eds.). The Cambridge handbook of violent behavior 503 and aggression. Cambridge University Press. 
504 Gorman-Smith, D., \& Tolan, P. (1998). The role of exposure to community violence and

505 developmental problems among inner-city youth. Development and psychopathology,

$506 \quad 10(1), 101-116$.

507 Gosling, S. D., Rentfrow, P. J., \& Swann, W. B., Jr. (2003). A Very Brief Measure of the Big

508 Five Personality Domains. Journal of Research in Personality, 37, 504-528.

509 Gurrola-Peña, G.M., Balcázar, P., Esparza Del Villar, O. A., Lozano-Razo, G., \& Zavala-Rayas,

510 J. 2018. Construction and Validation of the Contextual Victimization Questionnaire (CVCV) with Mexican Young Adults. International Journal of Emergency Mental Health and Human Resilience 20(3): 1-7.

513 Hernández, G. S., Ramos Lira, L., \& Méndez, M. T. S. (2004). Validación de las escalas de aceptación de la violencia y de los mitos de violación en estudiantes universitarios. Salud mental, 27(6), 40-49.

516 Herzberg, P. Y., \& Brähler, E. (2006). Assessing the Big-Five personality domains via short forms. European Journal of Psychological Assessment, 22(3), 139-148.

Hofmans, J., Kuppens, P., \& Allik, J. (2008). Is short in length short in content? An examination of the domain representation of the Ten Item Personality Inventory scales in Dutch language. Personality and Individual Differences, 45(8), 750-755.

Hu, L-T., \& Bentler, P. M. (1999). Cutoff criteria for fit indexes in covariance structure analysis: Conventional criteria versus new alternatives. Structural Equation Modeling, 6, 1-55.

INEGI, (2018) Encuesta Nacional de Seguridad Pública. Retrieved at: (1990-2017)". Retrieved at: 
Kline, R. B. (2011). Principles and practice of structural equation modelling. New York: The Guilford Press.

531
Matías, O. M. P., Andrade, N. A. O., Arenas, A. B. R., Cruz, R. G., \& Ramírez, M. A. R. (2013). Propiedades psicométricas del Cuestionario de Agresión en dos muestras diferentes de Hidalgo, México. European Scientific Journal, ESJ, 9(32).

Oshio, A., Shingo, A. B. E., \& Cutrone, P. (2012). Development, Reliability, and Validity of the Japanese Version of Ten Item Personality Inventory (TIPI-J). Japanese Journal of Personality, 21(1).

Osorio, J. (2015). The contagion of drug violence: spatiotemporal dynamics of the Mexican war on drugs. Journal of Conflict Resolution, 59(8), 1403-1432.

Pineda, D. A., Guerrero, O. L., Pinilla, M. L., \& Estupiñán, M. (2002). Utilidad de un cuestionario para rastreo del estrés postraumático en una población colombiana. Acta Neurol Colomb, 18(3), 132-138.

Pynoos, R. S., \& Eth, S. (1984). The child as witness to homicide. Journal of Social Issues, 40(2), 87-108.

Pynoos, R. S., \& Nader, K. (1988). Children who witness the sexual assaults of their mothers. Journal of the American Academy of Child \& Adolescent Psychiatry, 27(5), 567572 
549 Renau, V., Oberst, U., Gosling, S., Rusiñol, J., \& Chamarro, A. (2013). Translation and

550 validation of the ten-item-personality inventory into Spanish and Catalan. Aloma: Revista 551 de Psicologia, Ciències de l'Educació i de l'Esport, 31(2).

552 Santisteban, C., \& Alvarado, J. M. (2009). The aggression questionnaire for Spanish 553 preadolescents and adolescents: AQ-PA. The Spanish Journal of Psychology, 12(1), 320$554 \quad 326$.

555 Shahinfar, A., Kupersmidt, J. B., \& Matza, L. S. (2001). The relation between exposure to 556 violence and social information processing among incarcerated adolescents. Journal of 557 Abnormal Psychology, 110(1), 136-141.

558 Sobel, M. E. (1986). Some new results on indirect effects and their standard errors in covariance 559 structure models. In N. B. Tuma (Ed.), Sociological methodology (pp. 159-186). San Francisco: $560 \quad$ Jossey-Bass.

561 Teicher, M. H., \& Samson, J. A. (2016). Annual Research Review: Enduring neurobiological 562 effects of childhood abuse and neglect. Journal of child psychology and psychiatry, and 563 allied disciplines, 57(3), 241-266. doi:10.1111/jcpp.12507.

564 Velicer, W. F., Huckel, L. H., \& Hansen, C. E. (1989). A measurement model for measuring 565 attitudes toward violence. Personality and Social Psychology Bulletin, 15(3), 349-364. 
Figure 1

Figure 1: AMOS graphics for a structural equation model analyzing the effects of contextual violence on PTSD, and PTSD on disposition to aggression.

Positive and significant predictive effects of contextual violence on PTSD are observed, explaining $6 \%$ of the variance. Contextual violence and PTSD also have positive predictive effects on disposition to aggression, explaining $13 \%$ of the variance in responses to the Aggression Questionnaire. However, the indicators show a poor goodness of fit for this model $\left(\mathrm{Chi}^{2}=1404.1851, \mathrm{gl}=512, \mathrm{p}<.001, \mathrm{RMR}=.03647, \mathrm{GFI}=.92, \mathrm{AGFI}=88, \mathrm{CFI}=.943\right.$, RMSEA $=.077[\mathrm{Cl} 90 \%=.0623, .0932])$. Unstandardized estimates are shown.

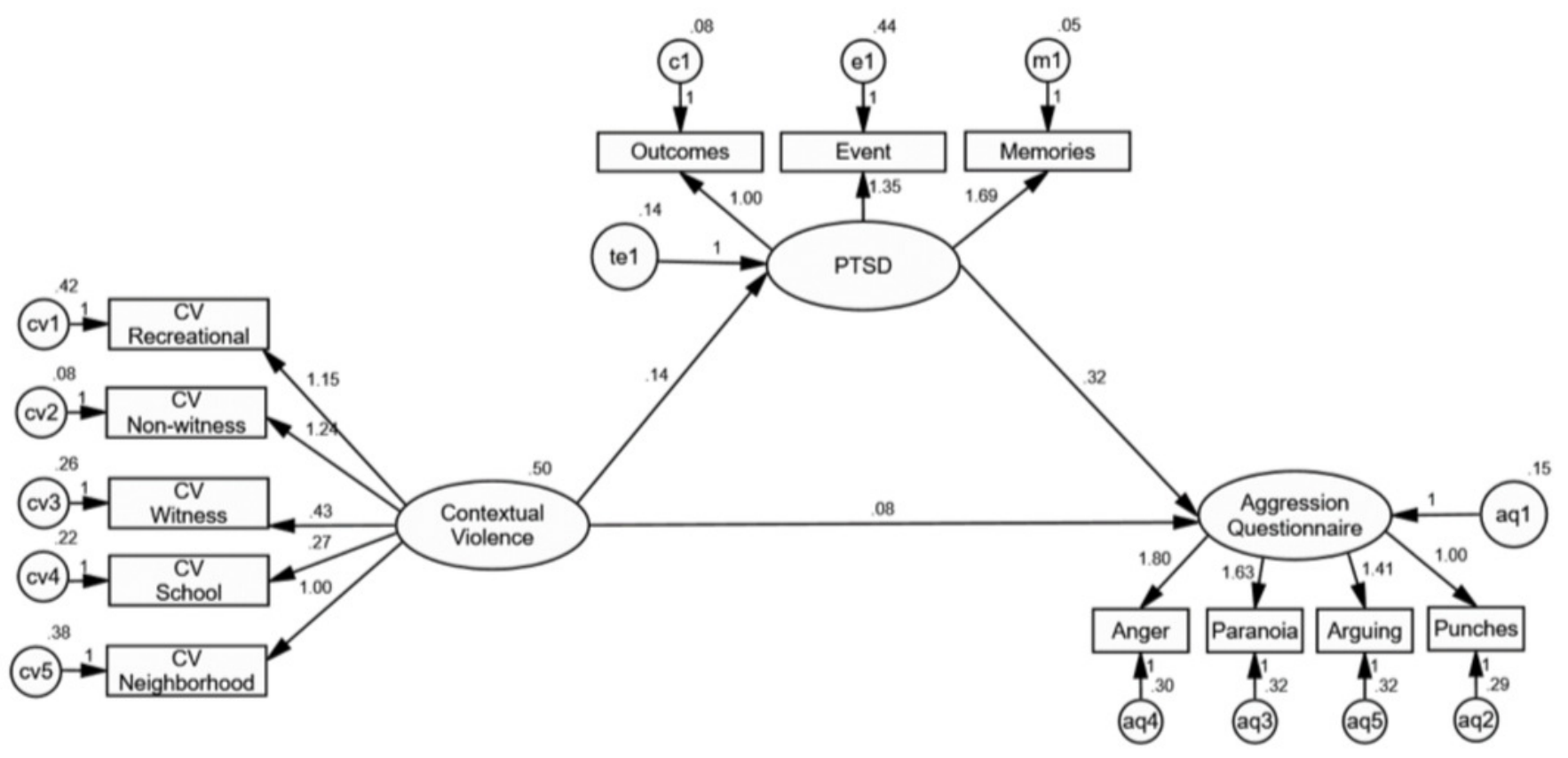


Figure 2

Figure 2: AMOS graphics for a structural equation model analyzing the effects of contextual violence at school and in the neighborhood on PTSD, and PTSD on disposition to aggression.

After keeping only contextual violence at school and in the neighborhood, best levels of explained variance were obtained for PTSD (13\%) and for aggression (17\%), besides best goodness of fit indexes comparing to the previous model ( $\chi 2=41.63, \mathrm{df}=21, \mathrm{p}=.005, \mathrm{RMR}$ $=.020, \mathrm{GFI}=.97, \mathrm{AGFI}=.93, \mathrm{CFI}=.97, \mathrm{RMSEA}=.058[\mathrm{Cl} 90 \%=.031, .083])$. Unstandardized estimates are shown.

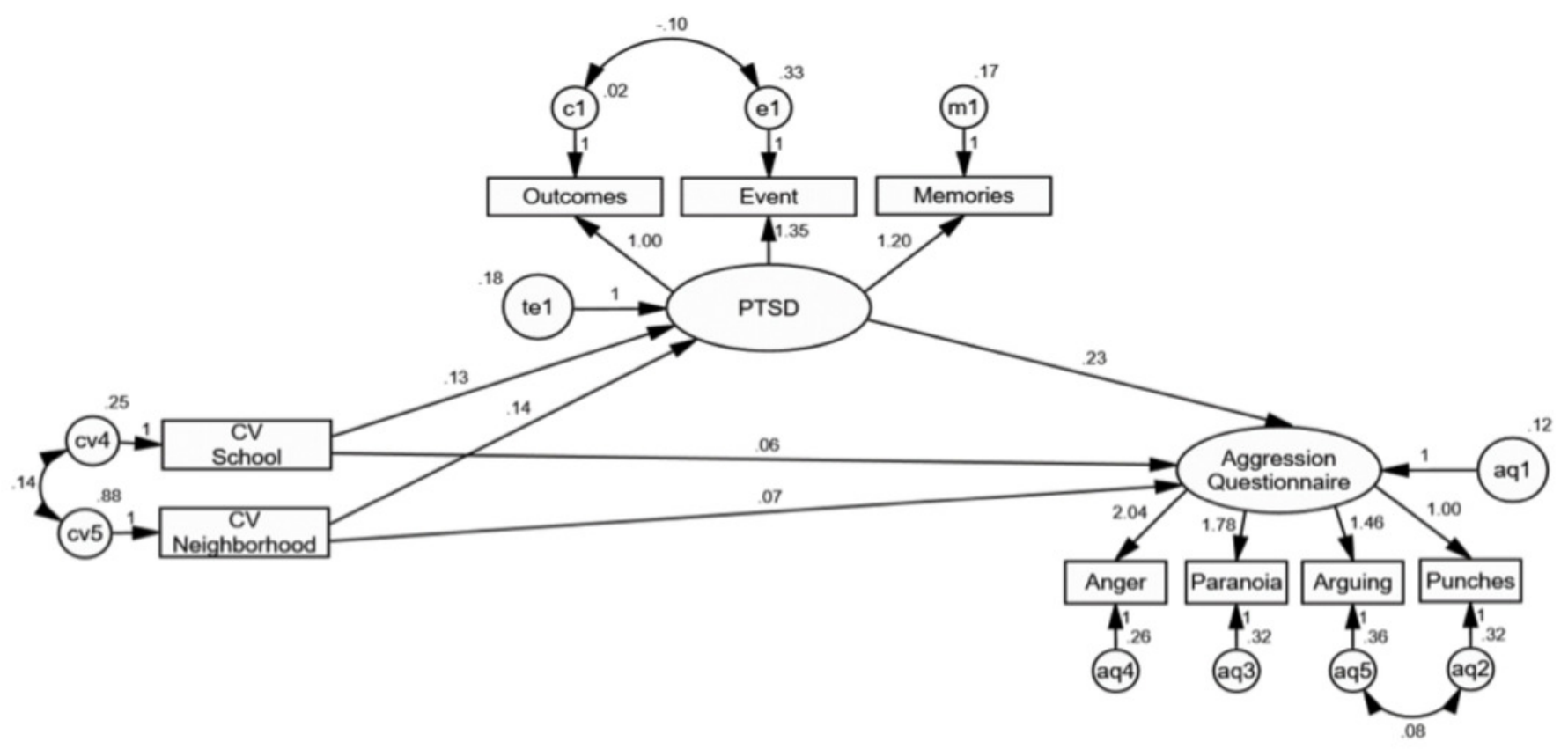


Figure 3

Figure 3: AMOS graphics for a multi-group comparison for women in the sample, analyzing a structural equation model of the effects of contextual violence at school and in the neighborhood on PTSD, and PTSD on the disposition to aggression.

Explained variance of PTSD and for aggression decreases notably for men and increases twice for women. Indirect effects of contextual violence at school and in the neighborhood remain statistically significant for women, but not for men. Contextual violence at school remains as a significant predictor of PTSD for women but not for men. Unstandardized estimates are shown.

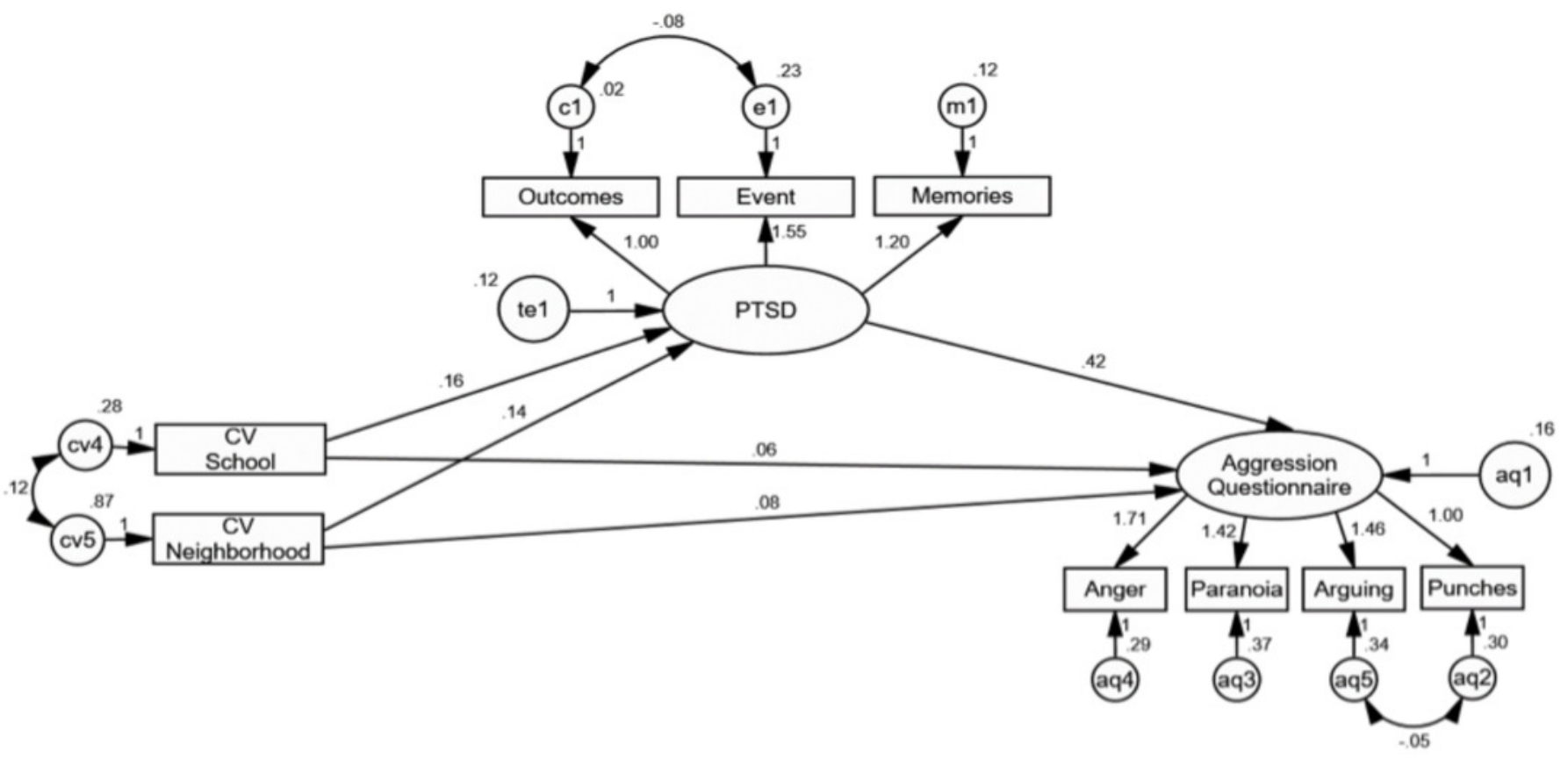


Figure 4

Figure 4: AMOS graphics for a multi-group comparison for men in the sample, analyzing a structural equation model SEM of the effects of contextual violence at school and in the neighborhood on PTSD, and PTSD on the disposition to aggression.

Explained variance of PTSD and for aggression decreases notably for men and increases twice for women. Indirect effects of contextual violence at school and in the neighborhood remain statistically significant for women, but not for men. Contextual violence at school remains as a significant predictor of PTSD for women but not for men. Unstandardized estimates are shown.

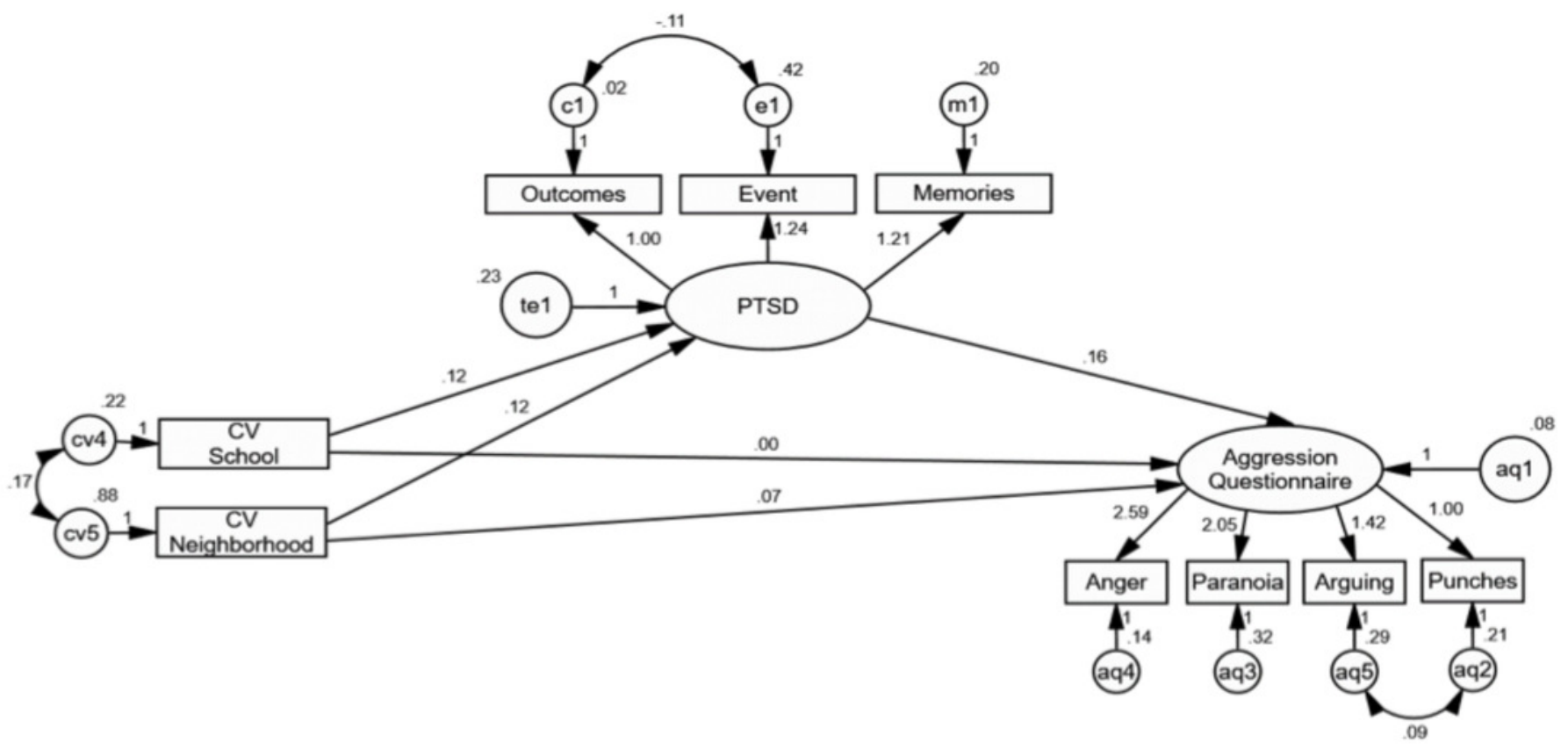




\section{Table $\mathbf{1}$ (on next page)}

Table 1: Main psychometric indicators and descriptive statistics of the factors identified in the instruments through factorial analysis $(n=298)$.

AQ: Aggression Questionnaire; CVCV: Community Victimization by Community Violence Scale; PTSD Post-Traumatic Stress Disorder; AVS: Acceptance of Violence Scale. 
1 Table 1. Main psychometric indicators and descriptive statistics of the factors identified in the

2 instruments through factorial analysis $(\mathrm{n}=298)$.

\begin{tabular}{|c|c|c|c|c|c|c|}
\hline Measure & Factor & Items & $\begin{array}{l}\text { Variance } \\
\text { explained }\end{array}$ & Alpha & Average & SD \\
\hline \multirow{5}{*}{ CVCV Scale } & $\begin{array}{l}\text { Non-witness contextual } \\
\text { victimization }\end{array}$ & 11 & $19.10 \%$ & .94 & 2.10 & .92 \\
\hline & $\begin{array}{l}\text { Contextual victimization in } \\
\text { the neighborhood }\end{array}$ & 8 & $15.49 \%$ & .91 & 2.46 & .94 \\
\hline & $\begin{array}{l}\text { Contextual victimization in } \\
\text { recreational areas }\end{array}$ & 4 & $9.53 \%$ & .90 & 2.58 & 1.04 \\
\hline & $\begin{array}{l}\text { Contextual victimization at } \\
\text { school }\end{array}$ & 5 & $8.43 \%$ & .77 & 1.33 & .50 \\
\hline & $\begin{array}{l}\text { Witness contextual } \\
\text { victimization }\end{array}$ & 4 & $8.35 \%$ & .82 & 1.29 & .59 \\
\hline Checklist for & Outcomes & 14 & $29.78 \%$ & .94 & 1.27 & .47 \\
\hline PTSD Traits & Memories & 8 & $19.70 \%$ & .91 & 1.53 & .68 \\
\hline Scale & Event & 2 & $9.70 \%$ & .80 & 1.58 & .84 \\
\hline \multirow{4}{*}{$\mathrm{AQ}$} & Punches & 7 & $14.49 \%$ & .82 & 1.61 & .67 \\
\hline & Paranoia & 6 & $11.98 \%$ & .81 & 2.16 & .87 \\
\hline & Anger & 5 & $11.93 \%$ & .83 & 2.1 & .92 \\
\hline & Arguing & 5 & $11.33 \%$ & .83 & 2.0 & .81 \\
\hline \multirow{3}{*}{ AVS } & $\begin{array}{l}\text { Acceptance of violence } \\
\text { against children }\end{array}$ & 6 & $28.66 \%$ & .88 & 1.49 & .60 \\
\hline & $\begin{array}{l}\text { Acceptance of couple } \\
\text { violence }\end{array}$ & 3 & $13.66 \%$ & .72 & 1.04 & .21 \\
\hline & $\begin{array}{l}\text { Acceptance of military } \\
\text { violence }\end{array}$ & 3 & $11.52 \%$ & .66 & 1.35 & .52 \\
\hline
\end{tabular}

3 AQ: Aggression Questionnaire; CVCV: Community Victimization by Community Violence Scale; PTSD

4 Post-Traumatic Stress Disorder; AVS: Acceptance of Violence Scale. 